\title{
Emergency Management Readiness of Pakistani Dentists at Public Sector Teaching Hospitals
}

Syed Jaffar Abbas Zaidi', Abdul Hafeez Shaikh'2, Shakeel Kazmi ${ }^{3}$, Muhtada Ahmad ${ }^{2}$, Ashar Afaq ${ }^{4}$, Afsheen Mansoor ${ }^{5}$ 'Department of Oral Biology, Dow Dental College, Dow University of Health Sciences, ${ }^{2}$ Department of Oral Surgery, Dow International Dental College, Dow University of Health Sciences, ${ }^{3}$ Department of Oral Biology, School of Dentistry, Shaheed Zulfiqar Ali Bhutto Medical University, ${ }^{4}$ Department of Community Dentistry, Dow International Dental College, Dow University of Health Sciences, ${ }^{5}$ Science of Dental Materials, School of Dentistry, Shaheed Zulfiqar Ali Bhutto Medical University, Islamabad, Pakistan.

\begin{abstract}
Background: Medical emergencies during dental treatment need to be appropriately equipped to deal with multiple chronic diseases in medically compromised patients. A well-prepared dental team can prevent stress-related medical emergencies. The objective of this study was to evaluate the readiness of dentists in managing medical emergencies, while comparing between postgraduate interns and registered dental graduates, working at a public sector hospital.
\end{abstract}

Methods: The study was conducted in three constituent dental colleges and affiliated hospitals of Dow University of Health Sciences situated in Karachi from January-March 2021. A 28-item validated questionnaire was piloted and designed to assess 250 dentists and interns in managing medical emergencies. For data analysis, responses of a three-point Likert scale related to knowledge was used, while a dichotomous scale was used for diagnosis and management and a p-value less than 0.05 was considered significant.

Results: Out of 250 dentists, 208(83\%) responded to the questionnaire. Most of the participants $200(96 \%)$ of the participants were taking medical histories and $149(87 \%)$ were routinely taking vital signs before dental treatment. We found that $62(42 \%)$ lacked adequate training for managing medical emergencies. Dental interns had more experience to deal with medical emergencies and were better prepared than general dentists.

Conclusion: Most of the participants lacked training in medical emergencies encountered in dental clinics. Concrete measures are needed to address this issue at a national level. Evidence-based recommendations, regular training, drills, and certification are needed to prepare the future dentist to deal with medical emergencies.

Keywords: Emergencies; Dental Clinics; Hospitals.

\section{Corresponding author:}

Dr. Syed Jaffar Abbas Zaidi

Department of Oral Biology,

Dow Dental College,

Dow University of Health Sciences,

Karachi, Pakistan.

Email: jaffar.zaidi@duhs.edu.pk

https://doi.org/10.36283/PJMD11-1/013

How to cite: Zaidi SJA, Shaikh AH, Kazmi S, Ahmad M, Afaq A, Mansoor A. Emergency Management Readiness of Pakistani Dentists at Public Sector Teaching Hospitals. 2022;1 (1): 78-84. doi: 10.36283/PJMD11-1/013 


\section{INTRODUCTION}

There has been a steady increase in the life span of the Pakistani population with more people living above 60 than ever before'. This shift has resulted in more individuals living with co-morbidities and taking multiple medications. An increasing number of elderly populations are now seeking dental treatment. Dentists are now seeing more patients with multiple chronic diseases and even medically compromised patients. These patients have complicated health histories coupled with complex drug histories. Every dental treatment carries a risk of a medical emergency. Chances of medical emergencies while treating these medically compromised patients increases significantly and specific modifications to dental treatment are required for these patients ${ }^{2}$.

Dentists now need to be prepared more than ever while treating these patients as medical emergencies can and do happen ${ }^{2}$. Fortunately, most medical emergencies are stress-related and can be prevented easily ${ }^{3}$. Some medical emergencies are life-threatening although their frequency is quite low, they end devastatingly. Death and significant morbidity have resulted from these medical emergencies. Dentists need to become more vigilant than ever before while treating patients with co-morbidities ${ }^{4}$.

Although medical emergencies are taught in undergraduate dental education through didactic lectures, less emphasis is placed on hands-on training and regular drills in dental clinics. Therefore, most general dentists working in dental clinics lack training in handling medical emergencies encountered in the dental office ${ }^{5}$. No mandatory core continuing professional development (CPD) or continuing medical education (CME) hours by the Pakistan Medical Commission have been dedicated to medical emergencies at the dental office. Furthermore, provincial health commissions and other regulatory bodies in Pakistan do not mandate dentists to maintain emergency drugs or possess oxygen cylinders in dental clinics. Based on the regional data available, the preparation of dentists in managing medical emergencies is lacking ${ }^{6,7}$. It is a dilemma in medical education that needs to be addressed through proper training, evaluation, and regular drills.

Little is known about the readiness of general dentists in Pakistan in managing medical emergencies in the dental office. There is a dire need to evaluate the training of dentists and their competence in managing medical emergencies. The objective of this study was to evaluate the readiness of dentists working at three public sector hospitals in managing medical emergencies encountered in dental offices. Furthermore, the level of preparation for medical emergencies was compared between the practicing dentists and postgraduates of three constituent dental colleges of Dow University of Health Sciences.

\section{METHODS}

The study was conducted in three constituent dental colleges of Dow University of Health Sciences situated in Karachi from January 6th till 15th March 2021. The research population $(n=250)$ included all registered dental practitioners, house officers, and postgraduate interns at Dow University of Health Science after taking consent. This study was conducted in commonly accepted educational settings and was following the ethical standards of the Helsinki Declaration. This study was exempted from ethical review as per Ref. No. ERC/3478/January/4/24. The anonymity and confidentiality of participants were guaranteed.

A 28-item self-constructed validated questionnaire was designed to assess the preparedness of dentists in managing medical emergencies and to evaluate their training, perception, and competence as undergraduates, graduates, and postgraduates to manage such events. This questionnaire was divided into three sections; the first section inquired about the sociodemographic and the second section concentrated on the preparedness of dentists in managing medical emergencies while the third section focused on the frequency of medical emergencies encountered in dental practices and training and certification aspects of dentists in managing medical emergencies.

This questionnaire was piloted on twenty general dentists for validity purposes before administering it in this study. The reliability of the questionnaire was confirmed based on Cronbach's alpha coefficient of 0.85. Data were analyzed using SPSS version 21. Items related to competence were computed in frequencies and percentages. For the convenience of analysis, responses of a three-point Likert scale related to knowledge while a dichotomous scale was used for diagnosis and management. The Chi-square test was conducted to assess the frequency distribution. A p-value less than 0.05 was considered statistically significant.

\section{RESULTS}

Out of the 250 questionnaires, 208(83\%) respondents returned filled questionnaires with a response rate of $83 \%$. Out of 208 respondents, 141(68\%) were females, and $67(32 \%)$ were males. Most of the respondents, $106(51 \%)$, were $20-25$ years old, followed by 61 (29\%), 26-30 years old, 30(14\%), 31-35 years old, $11(05 \%)>35$ years old. Likewise, more graduates, $107(51 \%)$ than postgraduate $101(49 \%)$, participated in the study. Most of the participants, $77(37 \%)$, were reported to have 1-3 years of work 
experience, followed by 51 (24\%) with < 1-year experience, $47(23 \%)$ with > 5-year experience, and $33(16 \%)$ with $4-5$ years of experience. Figure 1 shows the availability of emergency drugs and equipment in dental clinics as reported by dentists. Figure 2 depicts the occurrence of medical emergencies in dental practice.

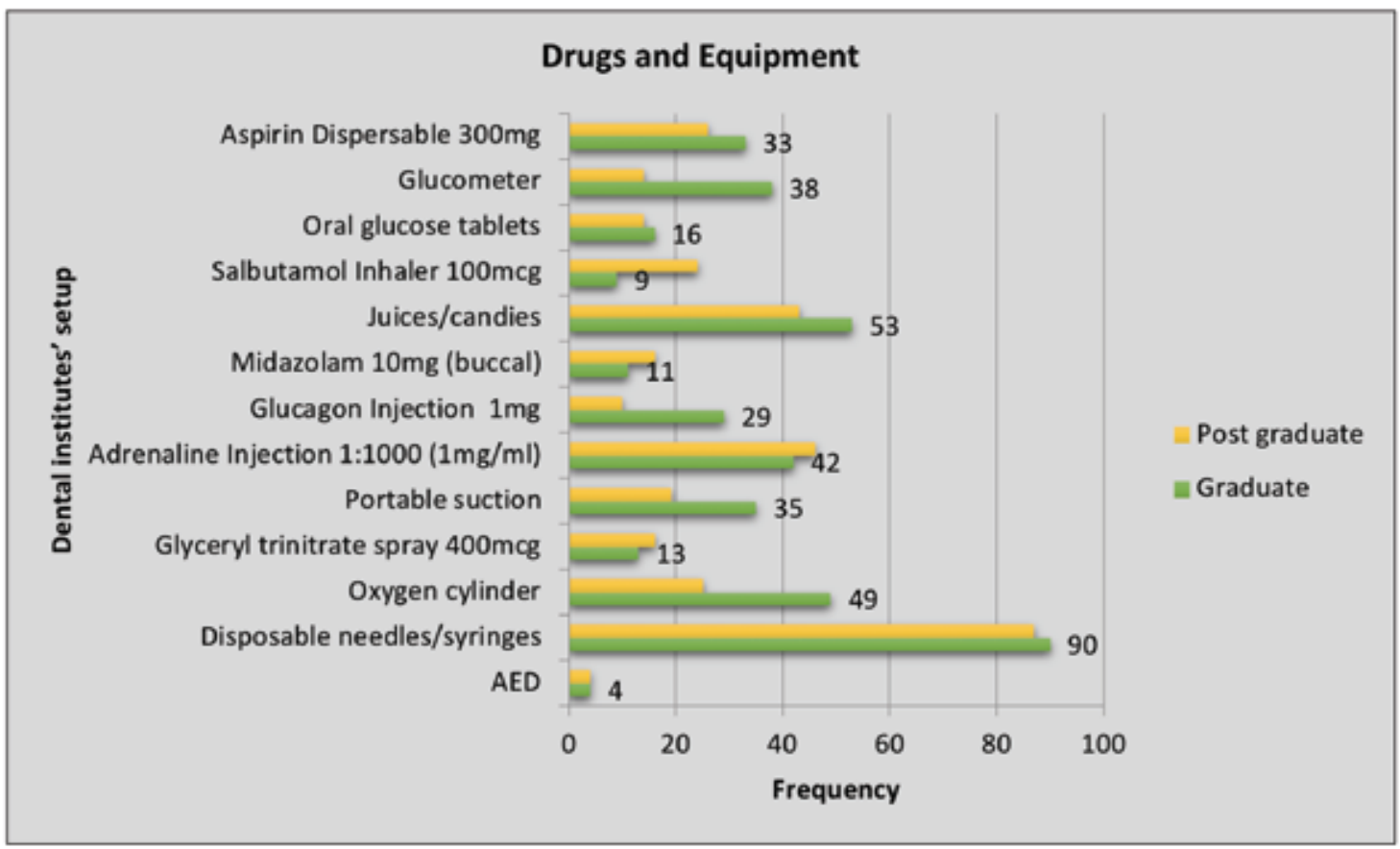

Figure 1: Emergency drugs and equipment in dental institutes' setup.

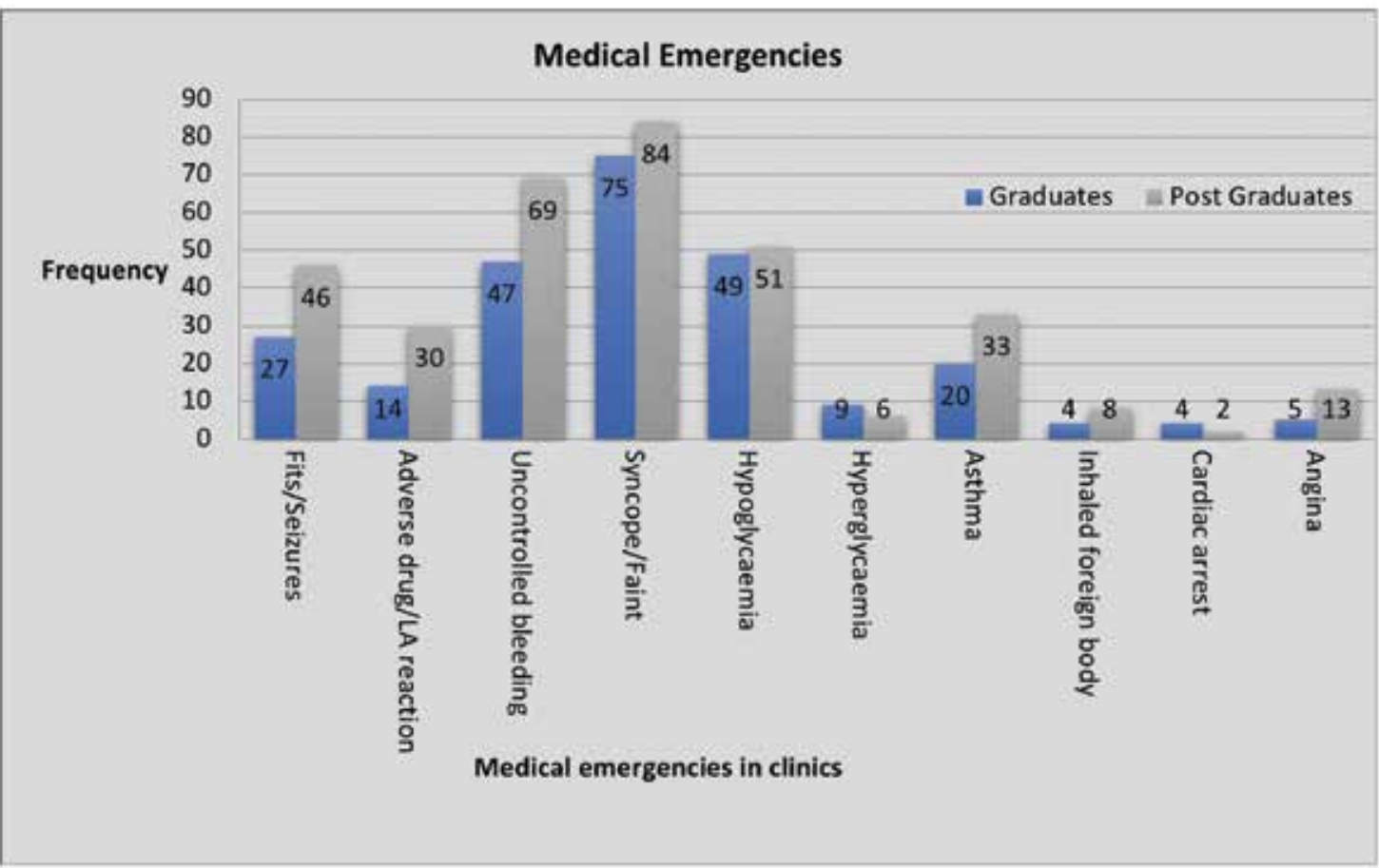

Figure 2: Medical emergencies encountered in dental clinics. 
Table 1: Statistical analyses of the responses by graduates and postgraduates.

\begin{tabular}{|c|c|c|c|c|c|c|c|}
\hline \multirow[b]{2}{*}{ Questions } & \multicolumn{2}{|c|}{ Graduate } & \multicolumn{2}{|c|}{ Postgraduate } & \multirow{2}{*}{$\begin{array}{l}95 \% \\
\text { Confidence } \\
\text { Interval }(\mathrm{Cl})\end{array}$} & \multirow[b]{2}{*}{$\begin{array}{l}\mathrm{X}^{2} \text { (Chi- } \\
\text { Square) }\end{array}$} & \multirow[b]{2}{*}{ p-Value } \\
\hline & $\begin{array}{l}\text { Always } \\
\text { n (\%) }\end{array}$ & $\begin{array}{c}\text { Sometimes } \\
\text { /Never } \\
\text { n (\%) }\end{array}$ & $\begin{array}{l}\text { Always } \\
\text { n (\%) }\end{array}$ & $\begin{array}{c}\text { Sometimes } \\
\text { /Never } \\
\text { n (\%) }\end{array}$ & & & \\
\hline \multicolumn{8}{|c|}{ Standard Operating Procedures } \\
\hline $\begin{array}{l}\text { Do you enquire about } \\
\text { medical history } \\
\text { including allergy? }\end{array}$ & $\begin{array}{c}102 \\
(95.3)\end{array}$ & $05(4.67)$ & $98(97.0)$ & $03(2.9)$ & $0.14-2.6$ & 0.47 & 0.52 \\
\hline $\begin{array}{l}\text { Do you inquire about } \\
\text { drug history from the } \\
\text { patient? }\end{array}$ & $\begin{array}{c}104 \\
(97.1)\end{array}$ & $12(11.2)$ & $90(89.1)$ & $11(10.8)$ & $0.94-1.00$ & 2.87 & 0.90 \\
\hline $\begin{array}{l}\text { Do you take informed } \\
\text { consent from the } \\
\text { patient before } \\
\text { performing any dental } \\
\text { procedure? }\end{array}$ & $95(88.7)$ & $12(11.2)$ & $90(89.1)$ & $11(10.8)$ & $0.40-2.30$ & 0.006 & 0.94 \\
\hline $\begin{array}{l}\text { Do you obtain the vital } \\
\text { signs before starting } \\
\text { any dental procedure? }\end{array}$ & $87(81.3)$ & $20(18.6)$ & $62(61.3)$ & $39(38.6)$ & $1.46-5.14$ & 10.14 & $0.00^{*}$ \\
\hline $\begin{array}{l}\text { Is emergency kit } \\
\text { available at your } \\
\text { dental institute? }\end{array}$ & $\begin{array}{c}106 \\
(99.0)\end{array}$ & $01(0.93)$ & $101(100)$ & $0(0)$ & $0.97-1.00$ & 0.98 & 0.33 \\
\hline \multicolumn{8}{|c|}{ Competencies } \\
\hline $\begin{array}{l}\text { Administering } \\
\text { intravenous injection }\end{array}$ & $38(35.5)$ & $69(64.5)$ & $39(38.6)$ & $62(61.4)$ & $0.5-1.54$ & 0.24 & 0.64 \\
\hline $\begin{array}{l}\text { Administering } \\
\text { intramuscularinjection }\end{array}$ & $45(42.1)$ & $62(57.9)$ & 81 (80.2) & 20 (19.8) & $0.09-0.33$ & 31.65 & $0.00^{*}$ \\
\hline Using a glucose meter & $79(73.8)$ & $28(26.2)$ & $83(82.2)$ & $18(17.8)$ & $0.31-1.19$ & 2.10 & 0.14 \\
\hline $\begin{array}{l}\text { Using } \\
\text { sphygmomanometer }\end{array}$ & $95(88.8)$ & $12(11.2)$ & $92(91.1)$ & 09 (8.9) & $0.31-1.92$ & 0.30 & 0.14 \\
\hline Cardiac compressions & $25(23.4)$ & $82(76.6)$ & $40(39.6)$ & $61(60.4)$ & $0.25-0.84$ & 6.37 & $0.01^{*}$ \\
\hline $\begin{array}{l}\text { Using an Ambu bag / } \\
\text { bag valve mask }\end{array}$ & 17 (15.9) & $90(84.1)$ & $31(30.7)$ & $70(69.3)$ & $0.21-0.83$ & 6.41 & $0.00^{*}$ \\
\hline Administering Oxygen & $24(22.4)$ & $83(77.6)$ & $33(32.7)$ & $68(67.3)$ & $0.32-1.10$ & 2.70 & 0.09 \\
\hline $\begin{array}{l}\text { Relieving foreign body } \\
\text { obstruction }\end{array}$ & $20(18.7)$ & 87 (81.3) & $32(31.7)$ & 69 (68.3) & $0.26-0.94$ & 4.67 & $0.03^{*}$ \\
\hline $\begin{array}{l}\text { Performing abdominal } \\
\text { thrusts (Heimlich } \\
\text { maneuver) }\end{array}$ & $20(18.7)$ & 87 (81.3) & $51(50.5)$ & $52(51.5)$ & $0.12-0.42$ & 23.37 & $0.00^{*}$ \\
\hline $\begin{array}{l}\text { Do you have a trained } \\
\text { dental staff for } \\
\text { assistance in any } \\
\text { medical emergency? }\end{array}$ & $42(39.3)$ & $36(33.6)$ & $20(19.8)$ & 74 (73.3) & $0.08-0.40$ & 14.77 & $0.00^{*}$ \\
\hline $\begin{array}{l}\text { Do you feel it is } \\
\text { important to have } \\
\text { competent staff for } \\
\text { emergencies? }\end{array}$ & $99(92.5)$ & $06(5.6)$ & $90(89.1)$ & $11(10.9)$ & $0.95-1.00$ & 1.90 & 0.16 \\
\hline
\end{tabular}

*Stastistically significant.

Table 1 highlights the statistical analyses of the responses by graduates and postgraduate interns. It would be two-fold statistically significant $(p<0.05)$ beneficial for the patients if graduates obtained the vital signs (blood pressure, pulse, temperature, respiration rate) before starting any dental procedure as compared to postgraduates. Moreover, $83 \%$ more post-graduate felt confident in administering intramuscular injection as compared to graduates and results are statistically significant $(p<0.05)$. Likewise, $39.6 \%$ of postgraduates were confident in performing cardiac compressions as compared to $23.4 \%$ of graduates. $31 \%$ of postgraduates were trained in using Ambu bag/bag valve masks com- pared to $17 \%$ of graduate dentists. $32 \%$ of postgradvates were confident in removing foreign body obstruction as compared to $20 \%$ of graduates. Lastly, $52 \%$ of postgraduates were more likely to perform the Heimlich maneuver in a conscious patient and abdominal thrusts in unconscious individuals as compared to $20 \%$ of graduates. Postgraduates were better prepared in performing emergency procedures as compared to graduate dentists. The postgraduates experienced more emergencies as compared to graduates. The responses were statistically significant $(p<0.05)$ except for hypoglycemia, hyperglycemia, inhaled foreign body, and cardiac arrest. 


\section{DISCUSSION}

Based on a strong body of evidence and feedback from medical emergency workshops, dentists are reluctant to use emergency drugs other than oxygen ${ }^{8}$. The most common response of dentists in a medical emergency is panicking'. Some doctors are unsure of how to assess a medical emergency and are uncomfortable treating these medical emergencies with medications ${ }^{2}$. Some life-threatening emergencies are inevitable, and they can happen at any time and anywhere. Dental clinics are no exception. Studies conducted globally show that medical emergency events are related to years of practice ${ }^{10,11}$. Doctors have an obligation to their patients to keep them safe while they are under their care. Although it is not a statutory or legal requirement in Pakistan, dentists need to be prepared for any medical emergency in their practice as it constitutes the standard of care, and no exceptions should be made in this regard.

Prevention and management of medical emergencies are taught in the undergraduate curriculum in the subjects of general medicine and oral medicine in the third year of the Bachelor of Dental Surgery (BDS) program as well as in oral surgery in the fourth year of BDS, as per the Pakistan Medical Commission (PMC) curriculum standards ${ }^{12}$. It is mostly taught didactically and assessed theoretically in most dental colleges in Pakistan ${ }^{13}$. Hands-on training, regular workshops, and basic life support (BLS) certification, and practical assessment strategies such as Objective Structured Clinical Examination (OSCE) and Mini Clinical Evaluation Exercise (mini-Cex) are needed to develop these lifesaving skills.

Research studies directed that most stress-related medical emergencies can be prevented using medical history and drug history ${ }^{3}$. Proper documentation of medical history and drug history in the patient records needs to be maintained and stored, although it is not mandated by any local or federal regulatory authority in Pakistan ${ }^{14}$. Studies further reported that vital signs were taken regularly before initiating dental treatment by the vast majority that is $149(71 \%)$ of the participants and this was statistically significant. Guidelines of the standard of care recommend that elevated blood pressure, increased body temperature, and elevated blood sugar levels preclude routine dental treatment, and such patients are referred and rescheduled once their vital signs are within normal parameters ${ }^{15}$.

In addition, participants were confident in using glucometer and blood pressure apparatus, but they were reluctant to administer oxygen, relieve foreign body obstruction and even perform the Heimlich maneuver. These findings are quite startling as studies conducted globally indicate that although dentists are reluctant to administer intravenous drugs but can administer oxygen easily. In our study, dentists were even hesitant to deliver oxygen to their patients ${ }^{16}$. This could be attributed to the low level of preparedness and low confidence in managing patients with foreign body obstruction. These findings are in concordance with studies conducted previously 17,18 .

Being unaware of the emergency number to dial in case of a medical emergency as reported by 129(62) of the participants of this study reflects on the lack of adequate training in medical emergencies. Medical emergencies in the dental office are managed until the patient is either stabilized or moved to a medical facility or an ambulance. For every minute that ensues, the chances of survival and irreversible brain damage in a cardiac arrest go down by 10 percent ${ }^{19}$. Many of the respondents were ill-equipped and unprepared in prompt referral and use of emergency drugs in a medical emergency. Syncope was one of the most frequently encountered medical emergencies as reported by $159(76)$ of the respondents of this study. The next most encountered medical emergency was hypoglycemia observed by $100(48 \%)$ of the participants followed by uncontrolled bleeding. The frequency of medical emergencies encountered in this study is in concordance with previous studies in Pakistan ${ }^{5,20}$.

Inadequate training related to handling medical emergencies was asserted by $54 \%$ of the participants. This was reflected by the self-reported inability of the vast majority $72 \%$ in performing BLS, gaining IV access, and even using emergency drugs including oxygen. These findings are like studies published in Saudi Arabia and Brazil ${ }^{21,22}$. Most of the respondents claimed that their practices were deficient in basic emergency drugs and none of the dental clinics at affiliated hospitals had Automated External Defibrillator (AED). These findings are quite alarming as all the participants are working in a public sector tertiary care hospital and if AEDs are not available to them, then the chances of dentists having AEDs working in isolated dental clinics are quite low. AEDs are considered life-saving devices in a cardiac-related medical emergency and dentists globally are increasingly keeping AEDs in their practice ${ }^{23,24}$.

Competent and trained dental staff for the management of medical emergencies was deemed important by $76 \%$ of the participants and that regular drills involving the whole team should be undertaken. The morbidity and mortality of medical emergencies in dental offices are related to the training of dental staff and their regular drills ${ }^{2,25}$. The Pakistan Medical Commission is the regulatory authority in medical education in Pakistan has not specified any core CPD hours for 
dentistry. The General Dental Council of the United Kingdom and Australian Dental Council has specified medical emergencies as a core CPD topic for dentists and is a mandatory requirement for a license to practice $26,27$.

\section{CONCLUSION}

The lack of preparedness for medical emergencies in dental clinics is quite alarming especially at tertiary care public teaching hospitals. Concrete steps are needed to address this issue at a national level. Medical emergencies at dental clinics are inevitable, and some are even life-threatening based on the findings of this study and other studies in Pakistan. Dentists have a duty of care towards their patients. Adequate training, certification, and regular drills can save the lives of patients attending dental clinics in Pakistan.

\section{ACKNOWLEDGMENTS}

The authors would like to acknowledge the university for facilitating the study.

\section{CONFLICT OF INTEREST}

The authors declare no conflict of interest.

\section{ETHICS APPROVAL}

This study was conducted in commonly accepted educational settings and was following the ethical standards of the Helsinki Declaration. This study was exempted from ethical review as per Ref. No. ERC/3478/January /4/24.

\section{PARTICIPANT CONSENT}

Only those participants were included in this study who consented. The anonymity and confidentiality of participants were guaranteed.

\section{AUTHOR'S CONTRIBUTION}

SJAZ had given the conception and performed the literature search. AHS wrote the manuscript. SK did the data collection and MA conducted the data analysis. AA did the data interpretation and piloting of the questionnaire. AM did the proofreading and Turnitin checks.

\section{REFERENCES}

1. Khan FN, Majeed MT. Education levels and life expectancy of males and females: Empirical evidence from Pakistan. J Arts Soc Sci. 2018; 5(1):96-114.

2. Rosenberg M. Preparing for medical emergencies: the essential drugs and equipment for the dental office. J Am Dent Assoc. 2010;141(1):14-19.

3. Hendler BH, Rose LF. Common medical emergencies: a dilemma in dental education. J Am Dent Assoc. 1975;91(3):575-382. doi: 10.14219/jada.archive.1975.0427

4. Assael LA. Acute cardiac care in dental practice. Dent Clin North Am. 1995;39(3):555-565.

5. Niaz AT, Zaidi J, Abbasi ZA. The nature and frequency of medical emergencies in dental offices of Karachi, Pakistan. Pak J Med Dent. 2020; 9(2):104-111. doi: 10.36283/PJMD9-2/018

6. Sangamesh NC, Vidya KC, Pathi J, Singh A. Awareness, Attitude, and knowledge of basic life support among medical, dental, and nursing faculties and students in the university hospital. J Int Soc Prev Community Dent. 2017;7(4):161-167. doi: 10.4103/jispcd.JISPCD_240_17

7. Somaraj V, Shenoy RP, Panchmal GS, Jodalli PS, Sonde L, Karkal R. Knowledge, attitude and anxiety pertaining to basic life support and medical emergencies among dental interns in Mangalore City, India. World J Emerg Med. 2017;8(2):131-135. doi: 10.5847/wjem.j.1920-8642.2017.02.009

8. Moore PA. The use of oxygen and airway modalities in dental office medical emergencies. Tex Dent J. 2004;121 (12):1150-1155.

9. Haas DA. Preparing dental office staff members for emergencies: developing a basic action plan. J Am Dent Assoc. 2010;141(1):8-13. doi: 10.14219/jada.archive.2010.0352

10. Müller MP, Hänsel M, Stehr SN, Weber S, Koch T. A state-wide survey of medical emergency management in dental practices: incidence of emergencies and training experience. Emerg Med J. 2008;25(5):296-300. doi: 10.1136/emj.2007.052936

11. Alexander RE, MCPhillips A. The state of preparedness in Texas dental practices for medical emergency responses: a survey. Tex Dent J. 2004;121 (12):1122-1230. doi:

12. Higher Education Commission [Internet]. BDS Curriculum: Higher Education Commission; 2011 [cited 2021 Oct 5]. Available from: https://hec.gov.pk/english/services/universities/RevisedCurricula/Documents/2010-2011/Draft-BDS-2011.pdf

13. Baig QA, Zaidi SJA, Alam BF. Perceptions of dental faculty and students of E-learning and its application in a public sector Dental College in Karachi, Pakistan. J Pak Med Assoc. 2019; 69(9):1319-1324.

14. Cederberg RA, Valenza JA. Ethics and the electronic health record in dental school clinics. J Dent Educ. 2012;76(5):584-589. doi: 10.1002/j.0022-0 337.2012.76.5.tb05292.x

15. Malamed SF. Knowing your patients. J Am Dent Assoc. 2010;141(1):3-7. doi: 10.14219/jada.archive.2010. 0350

16. Moore PA. Review of medical emergencies in dentistry: staff training and prevention. Part 1. Gen Dent. 1988;36(1):14-17.

17. Adewole RA, Sote EO, Oke DA, Agbelusi AG. An assessment of the competence and experience of dentists with the management of medical emergencies in a Nigerian teaching hospital. Nig Q J Hosp Med. 2009;19(4):190-194. doi: 10.4314/nqjhm.v19i4.54520

18. Bailey S, Bullock A, Cowpe J, Barnes E, Thomas H, Thomas $\mathrm{R}$, et al. Core continuing professional development (CPD) topics for the European dentist. Eur J Dent Educ. 2013;17(1):23-28. doi: 10.1111/eje.12047 19. Auble TE, Menegazzi JJ, Paris PM. Effect of 
out-of-hospital defibrillation by basic life support providers on cardiac arrest mortality: a metaanalysis. Ann Emerg Med. 1995;25(5):642-648. doi: 10.1016/S0196-0644(95)70178-8

20. Akhtar S, Rehman A, Ahmed W, Zaidi AB, Khalil $O$, Khan A. Knowledge, attitude and practices about medical emergencies among dental houseofficers working in two dental colleges. Pak Oral Dent J. 2019;39(2):133-136.

21. Gonzaga HF, Buso L, Jorge MA, Gonzaga LH, Chaves MD, Almeida OP. Evaluation of knowledge and experience of dentists of São Paulo State, Brazil about cardiopulmonary resuscitation. Braz Dent J. 2003; 14(3):220-222. doi: 10.1590/S0103-64402003000 300015

22. Al-Sebaei MO, Alkayyal MA, Alsulimani AH, Alsulaimani OS, Habib WT. The preparedness of private dental offices and polyclinics for medical emergencies. A survey in Western Saudi Arabia. Saudi Med J. 2015;36(3):335-340. doi: 10.15537/smj.2015.3.10047
23. Alexander RE. The automated external cardiac defibrillator: lifesaving device for medical emergencies. J Am Dent Assoc. 1999;130(6):837-845. doi: 10.14219/jada.archive.1999.0308

24. Boyd BC, Fantuzzo JJ, Votta T. The role of automated external defibrillators in dental practice. $\mathrm{N} \mathrm{Y}$ State Dent J. 2006;72(4):20-23.

25. ADA Council on Scientific Affairs. Office emergencies and emergency kits. J Am Dent Assoc. 2002;133(3):364-365. doi: 10.14219/jada.archive.2002.0176

26. Bailey S, Bullock A, Cowpe J, Barnes E, Thomas H, Thomas R, et al. Core continuing professional development (CPD) topics for the European dentist. Eur J Dent Educ. 2013;17(1):82-87. doi: 10.1111/eje.12047 27. Turner S, Ross MK, Ibbetson RJ. The impact of General Dental Council registration and continuing professional development on UK dental care professionals: (1) dental nurses. Br Dent J. 2012;213(2):1-7. doi: 10.1038/sj.bdj.2012.664. 